\title{
Perspectives of glutamine and its derivatives as feed additives for farm animals
}

\author{
S.G. Pierzynowski ${ }^{1,3}$ and A. Sjodin ${ }^{2,3}$ \\ ' Department of Animal Physiology, Lund University \\ Helgonavagen 3 b, SE-223 62 Lund, Sweden \\ 'Department of Public Health and Caring Sciences, Uppsala University \\ Box 609, SE-75125 Uppsala, Sweden \\ ${ }^{3}$ Gramineer International $A B$ \\ Ideon, 22370 Lund, Sweden
}

\begin{abstract}
Glutamine and its derivatives e.g., alpha-ketoglutaric acid (AKG) or ornithinc-alpha-ketoglutarate $(O K G)$ are molecules with a central role (via the Krebs cycle) in systemic, intestinal and gut bacterial metabolism. Studies have shown that AKG is a precursor not only of glutamine and arginine, but also of some other keto acids e.g., alpha-ketoisocaproate which in turn is a precursor of hydroxy-methyl-butyrate, which itself is regarded as a protein catabolic protector. Recently it has been postulated that $\mathrm{AKG}$ is not only an important energy donor, but that it also functions as an ammonium ion scavenger via transformation to glutamate, ornithine and putrescine and finally to GABA or succinate. Several beneficial effects of AKG have been reported in human medicine e.g., improved patients' recovery following gastrointestinal surgery. On the other hand, is was reported that 100 per cent glutamate metabolism in the first pass in infant pigs' small intestine. In the current presentation we discuss the potential benefits of using glutamine derivatives in human clinical nutrition as well as their role as feed additives in the production of farm animals.
\end{abstract}

KEY WORDS: feed additives, glutamine, alpha-keto-glutarate

\section{METABOLIC AND PHYSIOLOGICAL EFFECTS OF GLUTAMINE AND ITS DERIVATIVES}

In certain physiological and pathological conditions associated with acute or chronic malnutrition and/or hormonal stress, the human body shows signs of increased protein degradation or decreased protein synthesis, or both (Ahlman et al., 
1995; Petersson et al., 1995). This can result in retarded growth and/or a variety of complications in different organs. Even a slightly negative energy balance will lead to an increased excretion of nitrogen in the urine (Stanko et al., 1992). The increased nitrogen losses are the result of increased protein breakdown and/or decreased synthesis of proteins with associated increase in oxidation of amino acids. These alterations in protein metabolism can also be observed in association with even minor surgery (Hammarqvist et al., 1996) and may persist for periods of up to several weeks (Peterson et al., 1990, 1995). In order to counteract these changes, patients have been given total parenteral nutrition (TPN) pre- and post-operatively. However, despite administration of sufficient amounts of energy and protein a negative nitrogen balance has often been found (Essen et al., 1993).

The problem in situations such as illness, surgery, trauma, weight reduction or intensive exercise is that quantitative changes in nutritional intake may not be sufficient or in practice impossible to introduce. It is therefore of great importance to identify substrates with key functions in the regulation of protein metabolism under different physiological and pathological conditions involving metabolic stress.

\section{Glutamine}

The amino acid glutamine is one such substrate, which has attracted considerable interest in recent years (Newsholme et al., 1988). It has been extensively documented that the glutamine level in muscle is related to the breakdown and/or synthesis of muscle protein (Jepson et al., 1988; Millward et al., 1989; Vinnars, 1990). Supplementation with glutamine increases the glutamine level in muscle and thereby also improves the balance between breakdown and synthesis of muscle protein (Hammarqvist et al., 1989; Wernerman et al., 1989).

Despite the fact that metabolically stressed patients are a very heterogencous group, certain common findings are often reported. Problems of clinical importance include the facts that these patients often have a decreased nutritional uptake (malabsorption) and frequently show increased levels of bacteria in their blood (translocation of intestinal flora). It is known that the intestinal epithelial cells (enterocytes) are largely dependent on glutamine for their energy metabolism (Newsholme and Carrie, 1994) and that sufficient amounts of glutamine are necessary for their rapid division and proliferation and thereby for the normal absorptive function and for the integrity (barrier function) of the intestinal wall. Most of the glutamine required by the enterocytes comes directly from the intestinal lumen and not via the circulation.

A number of experiments with glutamine supplementation have been conducted in both animals and humans with disturbed intestinal function. Administration of extra glutamine to starved rats, and to rats given total parenteral nutrition (TPN) has been found to have positive effects in several studies, with structural improve- 
ments in the intestinal wall and reduced bacterial translocation (Inoue et al., 1993). Glutamine has also been shown to counteract damage to the intestinal wall caused by radiation, cytotoxic treatment (Skubitz and Andersson, 1996) or treatment with immunosuppressive agents (Ziegler et al., 1992; Zhang et al., 1995). Sepsis originating from the intestinal tract is a very common clinical problem in severely ill patients, and in both human and animal studies glutamine has been shown to have a protective effect (Gianotti et al., 1995). It has been postulated that sepsis stimulates protein synthesis in the enterocyte and that the availability of energy substrates (c.g. glutamine) regulates the activity of this synthesis (Higashiguchi et al., 1995).

Glutamine, as indicated above, has been relatively well examined in relation to metabolic stress and in many cases it has been shown to have promising effects on clinically relevant parameters. However, there are considerable practical difficulties associated with the use of glutamine. It is very unstable in solution, and complicated to handle in the clinical setting. In order to avoid these problems interest has been focused on precursors of glutamine, such as glutamic acid and alphaketoglutarate (AKG). Glutamic acid is highly stable but is unfortunately neurotoxic, can result in the "Chinese Restaurant Syndrome" and does not easily pass through cell membranes. AKG, the carbon skeleton of glutamine, is an intermediate in the Krebs cycle. It can be transaminated (by glutamate dehydrogenase) to glutamic acid, which can be further aminated (by glutamine synthetase) to form glutamine. This conversion is rapid. AKG is stable and non-toxic and is therefore a suitable precursor for endogenous glutamine synthesis.

Since AKG can "pick up" nitrogen, it is also able to "save" nitrogen while at the same time forming glutamine. This may be advantageous in several conditions of metabolic stress where protein breakdown is greater than protein synthesis and tissue levels of free glutamine are low (Walser, 1983).

\section{Alpha-ketoglutarate}

The effect of AKG as a supplement to TPN after surgery has been studied extensively. The effects of standard TPN and of TPN supplemented with cither branched-chain amino acids (BCAA), glutamine or alpha-ketoglutarate with or without ornithine were examined on markers of muscle protein homeostasis (Wernerman et al., 1990; Hammarqvist ct al., 1991). In this series of experiments it was demonstrated that the addition of BCAA to TPN had no beneficial effect whereas glutamine and ornithine alpha-ketoglutarate (OKG) both increased the glutamine level in muscle and improved the negative nitrogen balance. It was also shown that AKG given after cholecystectomy $(0.194 \mathrm{~g} / \mathrm{kg} / \mathrm{d}$, parenterally) improved the cumulative negative nitrogen balance over 3 days (from -9.9 to $-2.2 \mathrm{~g}$ ) and that supplementation with AKG increased the 


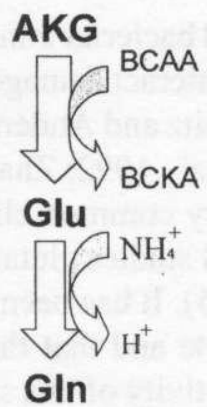

Figure 1. Metabolic transformation of alpha-keto-glutarate (AKG) to glutamate (Glu) and glutamine $(\mathrm{Gln}) . \mathrm{BCAA}=$ Branch chain amino acids, $\mathrm{BCKA}=$ Branch chain keto-acids

synthesis of muscle protein (polyribosomes). These findings are similar to earlier observations with glutamine and OKG.

The effect of AKG has also been investigated on energy metabolism in heart muscle during open heart surgery (extracorporeal circulation) (Kjellman et al., 1995). In a double-blind study, the effect of adding $28 \mathrm{~g} \mathrm{AKG}$ to the blood $(\mathrm{n}=13)$ before returning it to the normal circulation, was compared to a control group without AKG treatment $(n=10)$. Signs of damage to the heart muscle were evaluated $4 \mathrm{~h}$ after releasing the clamp. In the AKG-treated group the concentrations of both creatine kinase (CK) MB (32 vs. $49 \mu \mathrm{g} / \mathrm{L})$ and troponin T (1.1 vs. $2.0 \mu \mathrm{g} / \mathrm{L})$ were lower than those in the control group, indicating that $\mathrm{AKG}$ has a protective effect during ischemia and reperfusion of the heart muscle. In a similar experiment on rabbits (Bittle, 1983) the AKG-treated hearts were also found to have a better pump capacity.

High concentrations of ammonia in the blood is a clinical problem in cirrhosis of the liver. However, pyridoxine-AKG (Glutarase ${ }^{\circledR}, 1.8 \mathrm{~g} / \mathrm{d}$ ) given to 15 patients with liver cirrhosis reduced their ammonia levels (Salerno et al., 1983). In an animal experiment injection of potassium cyanide in rats resulted in unconsciousness in $100 \%$ of the animals and elevated ammonia levels ( 2.5 times normal) (Yamato, 1989). The effects of cyanide on ammonia level and consciousness could be abolished, however, by an injection of AKG $(500 \mathrm{mg} / \mathrm{kg}$ intraperitoneally). In the same study it was also found that the LD50 dose of cyanide doubled when the animals were pre-treated with AKG.

\section{$A K G$ in combination with ornithine}

In several experiments $\mathrm{AKG}$ has been administered as a salt in combination with the amino acid ornithine. Several of the publications on ornithine alpha-ketoglutarate $(\mathrm{OKG})$ originate from France, where this is a commercially available 


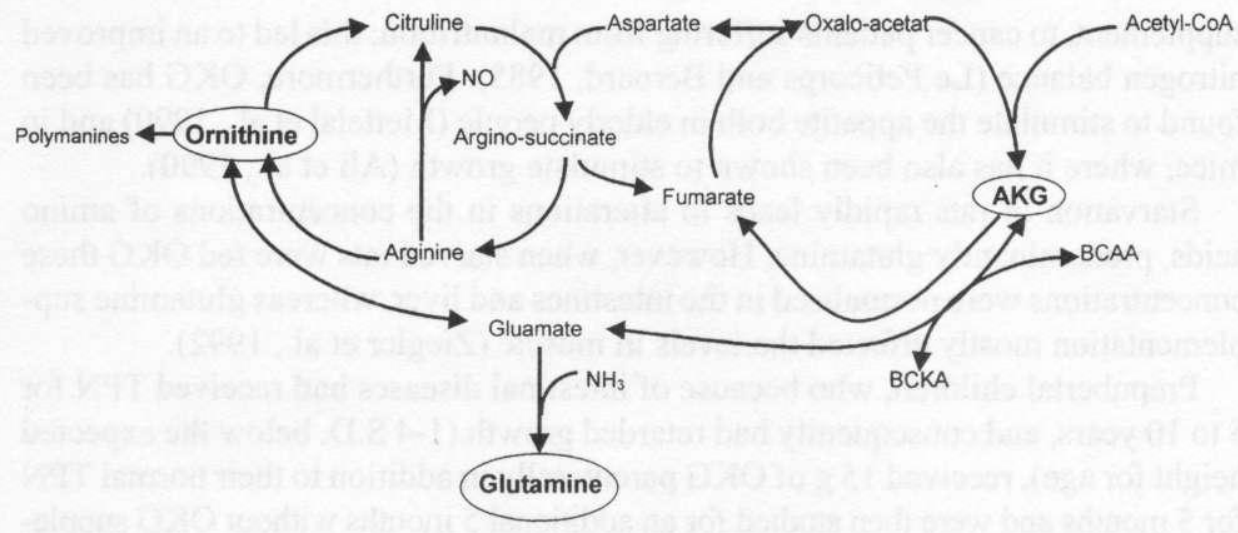

Figure 2. Common metabolic pathway for $\mathrm{AKG}$, ornithine and glutamine

compound $\left(\right.$ Ornecitil $\left.{ }^{\circledR}\right)$, and some of the experiments have only been reported in French. However, many of them are well covered in a review by Cynober (1991), who himself is responsible for a large part of the work done on OKG. It is not clear, however, to what extent the outcome of these experiments can be attributed to ornithine and to what extent to AKG. According to Cynober (1991), the salt OKG (Ornecitil ${ }^{\circledR}$ ) contains one molecule of AKG and two molecules of ornithine. Cynober states that the mechanisms/effects of AKG and ornithine are integrated, leading to results that are not seen with either AKG or ornithine alone (Cynober, 1991). However, Vinnars (1990) believes that it is the common carbon skeleton in AKG and glutamine that is metabolically important for protein metabolism, and in his own experiments he found no additional effect of ornithine, when given together with $\mathrm{AKG}$, over and above that of $\mathrm{AKG}$ alone.

Glutamine can be formed from $\mathrm{AKG}$, but it is also known that $\mathrm{AKG}$ will lead to the formation of $\alpha$-ketoisocaproate $(\alpha-\mathrm{KIC})$, which itself can stimulate protein synthesis in the liver and reduce muscle protein catabolism (Walser, 1983). Ornithine, on the other hand, has a central role in urea metabolism and is metabolized to arginine. Arginine is needed for synthesis of nitric oxide (NO) and will have an effect on the microcirculation. Both ornithine and arginine also stimulate the release of growth hormone $(\mathrm{GH})$, and ornithine is believed to stimulate the formation of aliphatic polyamines such as spermine and spermidine. Finally, both ornithine and AKG may increase the formation of glutamine (Cynober, 1991).

Malnourished elderly patients were given either $0,5,10$ or $20 \mathrm{~g}$ of OKG per day orally as a supplement to their ordinary food. Serum ferritin and albumin were found to increase in the subjects receiving 10 or $20 \mathrm{~g} / \mathrm{d}$, while no effects were observed in those who were given $5 \mathrm{~g} / \mathrm{d}$ or placebo (Brocker et al., 1985). In another study, $10 \mathrm{~g} / \mathrm{d}$ of OKG was given in addition to the normal food, as an oral 
supplement, to cancer patients suffering from malnutrition: this led to an improved nitrogen balance (Le Peticorps and Bernard, 1985). Furthermore, OKG has been found to stimulate the appetite both in elderly people (Mettelal et al., 1990) and in mice, where it has also been shown to stimulate growth (Ali et al., 1990).

Starvation in rats rapidly leads to alterations in the concentrations of amino acids, predominantly glutamine. However, when starved rats were fed OKG these concentrations were normalised in the intestines and liver, whereas glutamine supplementation mostly affected the levels in muscle (Ziegler et al., 1992).

Prepubertal children, who because of intestinal diseases had received TPN for 5 to 10 years, and consequently had retarded growth (1-4 S.D. below the expected height for age), received $15 \mathrm{~g}$ of OKG parenterally in addition to their normal TPN for 5 months and were then studied for an additional 5 months without OKG supplementation (Moukarzel et al., 1994). During the period of OKG supplementation the growth rate increased from $3.8 \mathrm{~cm} /$ year to $6.4 \mathrm{~cm} /$ year, but during the following control period it was again reduced to $3.6 \mathrm{~cm} /$ year. The $\mathrm{OKG}$ supplementation concomitantly increased the plasma levels of glutamine, glutamic acid and insulin like growth factor 1 (IGF-1). It was also found that the individual increases in growth rate correlated well with the increases in $\mathrm{lGF}-1(\mathrm{r}=0.82, \mathrm{P}<0.005)$.

$\mathrm{OKG}$ was also given to rats with large tumours without any effect on the nutritional status. However, when the tumour mass was reduced, OKG treatment resulted in an improved nitrogen balance, increased levels of BCAA and glutamine in skeletal muscle, and increased protein deposition in the intestines (Le Bricon et al., 1995). In another study on rats, by the same group, it was shown that compared to healthy control rats, animals bearing Yoshida ascites hepatoma showed a decreased food intake. Their body weight and protein synthesis were reduced and protein breakdown was increased (Le Bricon et al., 1994). In the tumour bearing rats that received 3.4-4.0 g OKG per $\mathrm{kg}$ body weight and day, protein breakdown decreased by one third, but OKG had no effect on tumour growth. In a control group receiving isonitrogenous amounts of glycine, no effects on protein metabolism were observed.

In another study, OKG ( $25 \mathrm{~g} / \mathrm{d}$ parenterally) or an isonitrogenous placebo were given to 36 multiple trauma patients for 6 days. In the OKG-treated cases the nitrogen balance improved (Mertes et al., 1988). In a controlled prospective study of patients with burns it was shown that the plasma and urinary concentrations of phenylalanine (a marker of protein catabolism in burns and sepsis) were restored to normal more quickly in a group receiving $\mathrm{OKG}(10 \mathrm{~g} / \mathrm{d}$ enterally). In a similar study it was also found that in patients receiving OKG nitrogen balance was attained sooner, the phenylalanine levels were lower and the levels of retinol binding protein (a marker of protein status) were higher compared with controls. In a study in rats that had received a standardised burn injury and in addition were kept on a diet resulting in negative energy balance, it was concluded that $\mathrm{OKG}$ 
limited the decrease in the glutamine level in muscle and the increase in protein catabolism, and reduced muscle wasting (for review see: Cynober, 1991).

The effects of parenterally given OKG have been examined in three different, controlled studies - in patients undergoing colorectal surgery (first study) or cholecystectomy (second and third studies). In the first study $25 \mathrm{~g}$ of $\mathrm{OKG}$ was substituted for $2.7 \mathrm{~g}$ nitrogen in the TPN for 3 days (Leander et al., 1985). In this group there was a decrease in urinary excretion of 3-methylhistidine (a marker of muscle protein degradation), and the creatinine and ammonia levels in the plasma were also reduced. In the second study, with a similar protocol, lower levels of glutamine in the muscle and a reduction of polyribosomes (markers of protein synthesis) were seen in the control group but not in the OKG-treated patients (Wernerman et al., 1987). In the final study it was shown that an amino acid supplement with additional $\mathrm{OKG}$ reduced the decreases in intramuscular glutamine 3 days after the operation, while supplementation with amino acids in general or with BCAA did not have this protective effect (Hammarqvist et al., 1990).

Lastly, OKG has been given to rats which underwent intestinal surgery and in addition received standardised radiation to their intestines (Kalefarenzos et al., 1996). In the supplemented group the intestinal integrity was shown to be better preserved (increased protein content, villi density, villi height and proliferative activity of the enterocytes) than in the control group, leading to fewer bacterial complications.

\section{GLUTAMINE AND ITS DERIVATIVES AS FEED ADDITIVES}

Modern nutrition tends to distinguish three target compartments of nutrient utilisation: 1. the peripheral tissues, 2. the gastrointestinal tract (GIT) mucosa, and 3. the GIT microflora. Glutamine and its derivatives seem to play an important role in all of them

\section{Peripheral tissues}

Before the food is utilised by the peripheral tissues it needs to be processed in the GIT; following digestion the elementary nutrients are absorbed and transported to the target peripheral tissues. The nutritional requirements are tissue-specific and change as well with the age of animal. In the peripheral tissues AKG/OKG, are active molecules in nitrogen metabolism, and when converted to glutamine they act as scavengers of ammonium ions thereby diminishing the concentration of ammonia in the blood and reducing nitrogen emission. By this mechanism AKG as a feed additive would be expected to diminish the metabolic stress in animal production by improving the efficiency of nitrogen metabolism (Olin et al., 1990). 
$\mathrm{AKG}$ and related compounds (glutamine, glutamate, $\mathrm{AKG}$ ) are indeed already recommended for use in geriatric medicine, postsurgical recovery strategies and sport nutrition because of their anabolic and protein preserving effects (Neu et al., 1996).

It has been postulated that the maximal body metabolism cannot exceed a 7-fold increase over the resting metabolic rate (Hammond and Diamond, 1997). Such a high acceleration of the biological machinery is rarely achieved. There are however some examples e.g., the high lactating dairy cow, the milking sow, quick growing nconates and also elite sportsmen (e.g., cyclist, athlete). Several limiting factors that cause farm animals not to achieve a harmonic high performance can be postulated: GIT limited performance including liver metabolism, insufficient blood circulation and lung function, inefficient metabolism because of non-balanced hormonal production, and immunological barriers.

\section{Gastrointestinal tract}

The metabolism of the gastrointestinal mucosa is particularly intensive, and it depends mostly on the luminal nutrient supply. The intestinal mucosa seems to utilise the products of dietary protein degradation (amino acids) as a major energy source. Thus, glutamine was demonstrated to be a major energy for the portal drained viscera in weaned piglets (Stoll et al., 1997). As well as an important role in the energetics of the GIT, $\mathrm{AKG}, \mathrm{OKG}$ and glutamine improve the integrity of the gastrointestinal tract (GIT) barriers. Consequently, there are a number of principal approaches that could be further investigated in relation to glutamine and its derivatives for usage as feed additives.

Firstly, glutamine effects on the intestinal absorption of nutrients, circulation of nutrients and macromolecules between blood and the intestinal lumen, function of immunological barrier and intestinal bacteria translocation need to be further evaluated.

Secondly, it is postulated that alimentary glutamine, AKG, OKG and proper protein digestion improve the overall gut barrier function and thus minimise susceptibility to bacterial translocation. Emphasis on GIT physiology and a better understanding of the relation between $\mathrm{AKG}$, nitrogen metabolism and a more proenvironmental animal production is necessary. The beneficial effect on the morphological structure of the GIT following total parenteral nutrition and anti-tumour radio- and chemotherapy has also been discussed (Kalefarenzos et al., 1996). AKG can protect the dietary amino acids from being utilised as energy by the gut. Gut and lung epithelium integrity can be maintained (Neu et al., 1996) by the help of new strategic feeding supplements (AKG).

Thirdly, studies are still needed to further explore the metabolic pathways and metabolic benefits of glutamine $\mathrm{OKG}, \mathrm{AKG}$ and its derivatives in the gastrointestinal tract (including gut microflora), liver and muscles. 
Fourthly, investigations need to be made of the function of $A K G$ as a scavenger of ammonium ions in the blood, as a way to improve animal well-being and to reduce nitrogen excretion.

\section{Gastrointestinal microflora}

In an ideal situation, the gastrointestinal microflora would not compete with the host for nutritional requirements. In practice, however, a certain amount of the diet (especially proteins) is utilised by the GIT microflora. To control bacterial growth the usage of antibiotics is very common. The primary role of feed antibiotics is to protect against bacterial overgrowth in the GIT in production animals fed with high protein diets. Today there is an increasing discussion concerning the use of antibiotics as feed additives (WHO, 1996; Best, 1997). On the one hand, medical experts stress the increased risk of generating resistant bacteria that might be transferred to man (Davies, 1996; Salyers, 1996). On the other hand, animal producers claim that animal performance and health will be diminished if antibiotics are banned in animal production (Viaene, 1997). One of the issues in modern nutrition of young animals - mainly pigs - is to find out to what extent non-antibiotic growth promoters and feed additives e.g., glutamine, $\mathrm{OKG}$ and AKG can reduce the need for antibiotic supplementation of animal feed. The research hypothesis and some preliminary data allow us to believe that $\mathrm{AKG}$, by increasing the integrity of the intestinal mucosal barrier, can in part reduce the risk of sepsis, and thereby the need for feed antibiotics. A reduced feed protein content, because of a better nitrogen utilisation from feed formulas supplemented with $\mathrm{AKG}$, would reduce not only nitrogen emission but also feed antibiotics.

$\mathrm{AKG}$ as an alternative to feed antibiotics could reduce the risk of increased bacterial resistance and as a result improve the effectiveness of antibiotics in both human and veterinary medicine (Salyers, 1996; Morell, 1997). Furthermore, by optimisation of animal feeds, using $\mathrm{AKG} / \mathrm{OKG}$ as a feed additive, it might also be possible to reduce the nitrogen emissions in farm animals.

\section{IMPLICATIONS}

The beneficial effects of physiological functional food (PFF) on human health are unquestionable. In Japan and in several other countries PFF food is a multibillion ECU market, being a product area which improves human health and the quality of life. So far the term PFF food does not exist in animal nutrition.

The main approaches of physiologically active feed additives - especially those for young animals, used directly after birth and around weaning are to improve so 
call "health" and growth. Treated with feed additives animals are very often "black boxes", and studies show the economical benefits and short term production consequences rather than the physiological or clinical relevance of the feed additives. Profound basic studies highlighting the effects of feed additives on metabolism, absorption etc. (quality of the product and long term effects on population performance), and on the environment are usually done post-factum when population or environmental consequences of feed additives are negative and very serious e.g., avaporcine (vancomycin) resistant Enterococcea. Usage of some other feed additives also need to be revised. Firstly, some of the feed additives provide doubtful benefits to the animal production if the right principles for feed optimisation are used in feed technology practice. Secondly, some of the feed additives contaminate the natural environment or can negatively act on long-term animal (population) health. Some other feed additives are crucially important, e.g., vitamins, minerals, immunoglobulins and amino acids with their derivatives.

The most important role for feed additives is to ensure the optimal utilisation of feed components, providing at the same time maximum security for animal shortterm (individual) and long-term (population) health and environment, but at the same time ensuring safety for consumers of the animal products. AKG is a very promising additive, which can solve that postulate in a complex manner, furthermore, it may become recognised as important for classifying feed as a PFF feed in future animal nutrition.

\section{REFERENCES}

Ahlman B., Ljunquist O., Persson B., Bindslev L., Wernerman J., 1995. Intestinal amino acid content in critically ill patients. JPEN 19, 272-278

Ali M.R, Jeevanandam M., Schiller W.R., 1990. Ornithine-alpha-ketoglutarate (OAKG) as a dietary supplement. FASEB J., Suppl. A807

Best P., 1997. European battle rages. Feed Intern. 18 (11), 8-11

Bittle J.A., 1983. Protection of ischemic rabbit myocardium by glutamic acid. Amer. J. Physiol. 245, H406-H412

Brocker P., Sassard F., Lods J.C., 1985. Influence de alpha-cetoglutarate diornethine sur liabumeremie et la transferrinemic des sujects ages denutris hospitalises. Rev. Geritr. 10233

Caine W., 1997. Ileal recovery of the endegenous amino acids in pigs. PhD Thesis, CIP data Koninklijke Bibliotheck, Den Haag, The Netherlands

Cynober L., 1991. Ornithine alpha-ketoglutarate in nutritional support. Nutrition 7. 313-322

Davies J., 1996. Bacteria on the rampage. Nature 383, 219-220

Essen P., McNurlan M., Sonnenfeld T., Milne E., Vinnars E., Wernerman J., Garlik P., 1993. Muscle protein synthesis after operation: effects of intravenous nutrition. Eur. J. Surg. 159, 195-200

Gianotti L., Alexander W., Gennari R., Pyles T., Babock G.F., 1995. Oral glutamine decreases bacterial translocation and improves survival in experimental gut-origin sepsis. JPEN 19,69-74 
Hammarqvist F., Wernerman J., Ali R., Vinnars E., 1990. Effects of an amino acid solution enriched with either branched chain amino acids or ornithine-alpha-ketoglutarate on the postoperative intracellular amino acid concentration of skeletal muscle. Brit. J. Surg. 77 , 214-218

Hammarqvist F., Wernerman J., von der Decken A., Vinnars E., 1991. Alpha-ketoglutarate preserves protein synthesis and free glutamine in skeletal muscle after surgery. Surgery $109,28-36$

Hammarqvist F., Wernerman J., Ali R., von der Decken A., Vinnars E., 1989. Addition of glutamine to total parenteral nutrition after clective abdominal surgery spares free glutamine in muscle, counteracts the fall in muscle protein synthesis, and improves nitrogen balance. Ann. Surg. $209,455-461$

Hammarqvist F., Westman B., Leijonmarck C-E., Andersson K., Wernerman J., 1996. Decrease in muscle glutamine, ribosomes, and the nitrogen losses are similar after laparoscopic compared with open chelecystectomy during the immediate postoperative period. Surgery 119, 417-423

Hammond K.A., Diamond J., 1997. Maximal sustained energy budgets in humans and animals. Nature 386, 457-462

Higashiguchi T., Noguchi Y., Meyer T., Fischer J.E., Hasselgren P-O., 1995. Protein in isolated enterocytes from septic endotoxic rats: regulation by glutamine. Clin. Sci. Colch. 89, 311-319

Inoue Y., Grant J.P., Snyder J.P., 1993. Effect of glutamine-supplemented total parenteral nutrition on recovery of small intestine after starvation atrophy. JPEN 17, 165-170

Jepson M.M., Bates P.C., Broadbent P., Pell J.M., Millward D.J., 1988. Relationship between glutamine concentration and protein synthesis in rat skeletal muscle. Amer. J. Physiol. 255, E166-E172

Kalefarenzos F., Spiliotis J., Melachrinou M., Katasarou Ch., Spiliopolou I., Panagopoulos C., Alexandries Th., 1996. Oral ornethine $\alpha$-ketoglutarate accelerates healing of the small intestine and reduces bacterial translocation after abdominal radiation. Clin. Nutr. 15, 29-33

Kalfarentzos F., Spilitos J., Melachrinou M., Katsarou Ch., Spiliopoulou I., Panagopoulus C., Morell V., 1997. Bacteria diversity through warfare. Science 278,575

Kjellman U., Bjork K., Ekroth R., Karlsson H., Jagenburg R., Nilsson F., Svensson G., Wernerman J., 1995. Alpha-ketoglutarate for myocardial protection in heart surgery. Lancet 345, 552-553

Leander U., Furst P., Vesterberg K., 1985. Nitrogen sparing effect of Ornicetil in the immediate postoperative state. Clinical biochemistry and nitrogen balance. Clin. Nutr. 4, 43

Le Bricon T., Cynober L., Baracos V.E., 1994. Ornithine alpha-ketoglutarate limits muscle protein breakdown without stimulating tumor growth in rats bearing Yoshida ascites hepatoma. Metab. Clin. Exp. 43, 899-905

Le Bricon T., Cynober L., Field C.J.. Baracos V.E., 1995. Supplemental nutrition with ornithine alpha-ketoglutarate in rats with cancer-associated cachexia: surgical treatment of tumor improves efficacy of nutritional support. J. Nutr. 125, 2999-3010

Le Peticorps A.M., Bernard P.F., 1985. Alpha-cetoglutarate diornethine en nutrition eneteral exclusive. Med. Chir. Dig. 14, 441

Mertes N., M^llman M., Pfister M., Furster P., Puchstein C., Nolte G., Winde G., 1988. Nitrogen sparing effect of Ornicitil-supplemented TPN in hypercatabolic septic or polytraumatized patients. In: Soeters, Wilson, Holm (Editors). Advances in ammonia metabolism and hepatic encephalopathy. Elsevier, Amsterdam, pp. 141

Mettelal J.F., Wolmarck Y., Bertaux P., 1990. Comparison en double aveugle des effets de líoxoglutarate diornethine sur le comportement alimentair des sujets ages. Rev. Geritr. 15, 353

Millward D.J., Jepson M.M., Omer A., 1989. Muscle glutamine concentration and protein turnover in vivo in malnutrition and in endotoxemia. Mctabolism 28, Suppl. 1, 6-13

Morell V., 1997. Bacteria diversity through warfare. Science 278,575 
Moukarzel A., Goulet O., Salas J.S., Martihnneberg C., Buchman A.L., Cynober L., 1994, Growth retardation in children receiving long-term total parenteral nutrition: effects of ornethine alphaketoglutarate. Amer. J. Clin. Nutr. 60, 408-413

Neu J., Shenoy V., Chakrabarti R., 1996. Glutamine nutrition and metabolism: where do we go from here? FASEB J. 10, 829-837

Newsholme E.A., Carrie A.L., 1994. Quantitative aspects of glucose and glutamine metabolism by intestinal cells. Gut 35, Suppl. 1, S13-S17

Newsholme E.A., Newsholm P., Curi R., Challoner M.A., Ardawi M.S.M., 1988. A role for muscle in immune system and its importance in surgery, trauma, sepsis and burns. Nutrition 4, 261-268

Nissen S., Sharp R., Ray M., Fuller J.C. Jr., Connelly A.S., Abumrad N., 1996. Effect of leucine metabolite betha -hydroxy-methylbuturate on muscle metabolism during resistance-exercise training. J. Appl. Physiol. 81, 2095-2104

Olin T., Jungvid H., Von der Decken A., 1992. Effect of dietary keto acids on intermediary metabolism of nutrients in Atlantic salmon (Salmo salar) during 17-betha-estradiol-induced vitellogenin synthesis. Anim. Sci. 42, 246-253

Petersson B., Hultman E., Andersson K., Wernerman J., 1995. Human skeletal muscle protein: effect of malnutrition, elective surgery and total parental nutrition. Clin. Sci. Col. 88, 479-84

Peterson B., Wernerman J., Waller S.-O., von der Decken A., Vinnars E., 1990. Elective abdominal surgery depresses muscle protein synthesis and increases subjective fatigue: effects lasting more than 30 days. Brit. J. Surg. 77, 796-800

Raul F., Gosse F., Galluser M., Hasselmann M., Seiler N., 1995. Functional and metabolic changes in intestinal mucosa of rats after enteral administration of ornithine alpha ketoglutarate salt. J. Parent. Ent. Nutr. 19, 145-150

Reeds P.J., Burrin D.G., Jahoor F., Wykes L., Henry J., Frazer E.H., 1996. Enteral glutamate is almost completely metabolized in first pass by the gastrointestinal tract of infant pigs. Amer. $\mathrm{J}$. Physiol. 270, E413-E418

Salerno F., Abbiati R., Fici F., 1983. Effect of pyridoxine alpha-ketoglutarate (PAK) on ammonia and pyruvic and lactic acid blood levels in patients with cirrhosis. Int. J. Clin. Pharmacoi. Res. 3, $21-25$

Salyers A., 1996. The real threat from antibjotics. Nature 384,304

Skubitz K.M., Andersson P.M., 1996. Oral glutamine to prevents chemotherapy induced stomatitis: A pilot study. J. Lab. Clin. Med. 127, 223-228

Stol B., Burrin D.G., Jahoor F., Yu H.H., Reeds P.J., 1997. Diatery protein is the maior source of energy for the portal drained viscera of fed piglets. Proceedings of 14th Symposium on Energy Metabolism of Farm Animals. Newcastle, Ireleand, Working Pre-publication Papers, 3-4

Walser M., 1983. Rationale and indications for the use of alpha-ketoanalogues. JPEN 8, 37

Wernerman J., Hammarqvist F., Ali R., Vinnars E., 1989. Glutamine and ornithinc-alpha-ketoglutarate but not branched-chained amino acids reduce the loss of muscle glutamine after surgical trauma. Metabolism 38, Suppl. 1, 63-66

Wernerman J., Hammarqvist F., Vinnars E., 1990. Alpha-ketoglutarate and postoperative muscle catabolism. Lancet $335,701-703$

Wernerman J., Hammarqvist F., von der Decken A., Vinnars E., 1987. Ornithine-alpha-ketoglutarate improves skeletal muscle protein synthesis as assessed by ribosome analysis and nitrogen balance postoperatively. Ann. Surg. 206,674

WHO., 1996. The Medical Impact of the Use of Antimicrobials in Food Animals. Report of a WHO Meeting in Berlin, October 13-17

Viaene J., 1997. Antimicrobials ban hits Swedish production. Feed Mix 5, 27 
Vinnars E., 1990. Role of glutamine and its analogs in posttraumatic muscle protein and amino acid metabolism. JPEN 14, Suppl. 4, 125S-129S

Yamato H., 1989. Hyperammoniemia, increased brain neutral and aromatic amino acid levels, and encephalopathy induced by cyanide in mice. Toxicol. Appl. Pharmacol. 99, 415-420

Zhang W., Frankel W.L., Bain A., Choi D., Klurfeld D.M., Rombeau J.L., 1995. Glutamine reduces bacterial translocation after small bowel transplantation in cyclosporine-treated rats. J. Surg. Res. 58, 159-164

Ziegler F., Coudray-Lucas C., Jardel A., Lasnier E., Le Boucher J., Ekindjian O.G., Cynober L., 1992. Ornethine alpha-ketoglutarate and glutamine supplementation during refeeding of fooddeprived rats. J. Parent. Ent. Nutr. 16, 505-510 